\title{
Dyeing of Polyester and Polyamide Synthetic Fabrics with Natural Dyes Using Ecofriendly Technique
}

\author{
Khaled Elnagar, ${ }^{1}$ Tarek Abou Elmaaty, ${ }^{2}$ and Sally Raouf ${ }^{2}$ \\ ${ }^{1}$ Chemical Metrology, National Institute of Standards, Cairo 12211, Egypt \\ ${ }^{2}$ Department of Textile Printing, Dyeing and Finishing, Faculty of Applied Arts, Damietta University, Damietta 34512, Egypt \\ Correspondence should be addressed to Tarek Abou Elmaaty; tasaid@du.edu.eg
}

Received 28 July 2014; Revised 30 October 2014; Accepted 31 October 2014; Published 24 November 2014

Academic Editor: Ricardo Molina

Copyright (c) 2014 Khaled Elnagar et al. This is an open access article distributed under the Creative Commons Attribution License, which permits unrestricted use, distribution, and reproduction in any medium, provided the original work is properly cited.

\begin{abstract}
This work presents an ecofriendly method for dyeing synthetic fabrics with natural dyes using UV/ozone pretreatment to activate fiber and improve dyeability of polyester and nylon. Fabrics are pretreated with UV/ozone for different periods of time ranged from $5 \mathrm{~min}$ to $120 \mathrm{~min}$. Effect of pretreatment on surface morphology was studied by scanning electron microscope (SEM). Mechanical behavior was studied by testing tensile strength and elongation percentage. Chemical modification of the surface was studied using attenuated total reflection Fourier transform infrared spectrometer (ATR-FTIR). Dyeability of the treated samples was investigated in terms of their colour strength expressed as $K / s$ in addition to fastness to washing and light. This research showed the increment of the affinity of the studied synthetic fabrics towards curcumin and saffron natural dyes using ecofriendly technique.
\end{abstract}

\section{Introduction}

With the continued increase in the use of synthetic fibers in the last fifteen years, many investigations have been carried out with the objective of obtaining a better understanding of improving chemical and physical properties of synthetic fibers.

These fibers surpass the production of natural fibers with a market share of $54.4 \%$. The advantages of these fibers are their high modulus and strength, stiffness, stretch or elasticity, wrinkle and abrasion resistances, relatively low cost, convenient processing, tailor-able performance, and easy recycling. The downside to synthetic fibers use are reduced wearing comfort, build-up of electrostatic charge, the tendency to pill, difficulties in finishing, poor soil release properties, and low dyeability. These disadvantages are largely associated with their hydrophobic nature. To render their surfaces hydrophilic, various physical, chemical, and bulk modification methods are employed to mimic the advantageous properties of their natural counterparts [1].

The classical chemical modification of synthetic polymers, using strong alkaline or acid agents, requires high amounts of energy and chemicals (binders, coupling agents, etc.), which are partially discharged to the environment. Furthermore, some of the substances used, due to their weak bonding, are released from the end-products, presenting potential health risks and reducing the technical lifetime of the products. Although alkaline products render synthetic fibres more hydrophilic, they also lead to the deterioration of other properties causing irreversible yellowing and loss of resistance. In order to reduce the use of such chemicals and their environmental impact, new technologies have been developed to replace classical methodologies $[2,3]$.

One of the potentially more effective and economical methods for synthetic fabrics surface modification is ultraviolet ozone $\left(\mathrm{UV} / \mathrm{O}_{3}\right)$ treatment with significant depth. In $\mathrm{UV} / \mathrm{O}_{3}$ treatment, two different UV radiations are present. One has a wavelength of $184.9 \mathrm{~nm}(\lambda 1)$, and the other has a wavelength of $253.7 \mathrm{~nm}(\lambda 2)$. When the molecules on the surface of synthetic polymers are exposed to the UV lights, excitation and dissociation of the polymeric molecules by the short-wavelength UV radiation take place. This is known as a photosensitized oxidation process. This treatment, also, changes the surface morphology and topography of the polymer. The SEM (scanning electron microscopy) images of the samples showed a marked increase in the grain size and the 
surface roughness of the irradiated polymer in comparison to the surface of the untreated samples. This method is suitable for synthetic fabric pretreatment and does not cause damage by heat to the fabrics because the modification is carried out under mild thermal conditions (or low temperatures). Thus, beneficial improvements to synthetic fabrics dyeability, printability, and shrink resistance properties can be achieved $[4,5]$.

In the recent years, there has been a trend to revive the art of natural dyeing. This is a result of the stringent environmental standards imposed by many countries in response to the toxic and allergic reactions associated with synthetic dyes. Natural dyes are more ecofriendly than synthetic dyes and can exhibit better biodegradability and generally have a higher compatibility with the environment $[6,7]$.

This study is to improve the hydrophilicity of synthetic fabrics via $\mathrm{UV} / \mathrm{O}_{3}$ irradiation and to impart deep coloring effect of the irradiated synthetic fabrics when dyed with natural dyes.

\section{Experimental}

\subsection{Materials}

2.1.1. Fabrics. In this study, $100 \%$ scoured and bleached plain weave polyester $\left(109 \mathrm{~g} / \mathrm{m}^{2}\right)$, nylon $\left(119 \mathrm{~g} / \mathrm{m}^{2}\right)$ fabrics were used. Fabrics were purchased from Misr for Spinning and Weaving Company, Mahalla El-Kobra, Egypt.

2.1.2. Natural Dyes. Curcumin and saffron were purchased from Riedel de Haen Ag Seelze Hannover Company, Germany, and were used as natural dyes.

2.1.3. Chemicals. Ferrous sulphate $\left(\mathrm{FeSO}_{4}\right)$ was used as a mordant, and sodium sulphate and sodium carbonate were purchased from Algmohria Company, Egypt, and were used as chemicals reagent.

\subsection{Methods}

2.2.1. UV/Ozone Treatment. $\mathrm{UV} / \mathrm{O}_{3}$ irradiation was carried out using high intensity; low-pressure mercury lamp without outer envelope (LRF 02971, 200 watts, 220 volts, made in Poland) was placed in a cubic box of side length $60 \mathrm{~cm}$. Samples' strips were hanged around the source at a distance $(\sim 20 \mathrm{~cm})$, for different periods $5,20,50,110$, and 120 minutes, respectively $[8,9]$.

\subsubsection{Dyeing Procedure}

(A) Mordanting. The polyester and nylon fabrics were premordanted by treating in a bath containing ferrous sulphate $6 \%$ (owf) keeping material to liquor ratio $1: 15$ at $60^{\circ} \mathrm{C}$ for 60 min followed by rinsing with cold water and well drying [10].<smiles>COc1cc(/C=C/C(=O)CC(=O)/C=C/c2ccc(O)c(OC)c2)ccc1O</smiles>

FIGURE 1: Chemical structure of curcumin.

(B) Dyeing with Natural Dyes. All the dyeing experiments were carried out by exhaustion method in a water bath containing the dye extract.

(1) Dyeing with Curcumin Dye. The premordanted polyester and nylon fabrics were introduced, respectively, into the dye bath containing $2 \%$ curcumin dye (Figure 1) at a material-toliquor ratio $1: 15$ at $70^{\circ} \mathrm{C}$ in the presence of $50 \mathrm{gm} / \mathrm{L}$ sodium sulphate to promote exhaustion. Dyeing was maintained for $100 \mathrm{~min}$. The dyed samples were washed with cold water and dried well at room temperature $[10,11]$.

(2) Dyeing with Saffron Dye. The premordanted polyester and nylon fabrics were introduced, respectively, into the dye bath containing 5\% saffron dye (Figure 2) at room temperature which then increased to $85^{\circ} \mathrm{C}$ with gentle stirring, keeping the liquor ratio $1: 30$. The dyeing was then continued for one hour at $\mathrm{pH} 7-8$ using $2 \mathrm{gm} / \mathrm{L}$ of sodium carbonate. After dyeing the samples were taken out of the bath and thoroughly washed with water [12].

\subsection{Measurements and Analysis Testing}

2.3.1. SEM Analysis. The scanning electron microscope (SEM) photographs were carried out for samples under our study using SEM Model Philips XL 30, with accelerating voltage $30 \mathrm{kV}$, magnification 10x up to $400.000 \mathrm{x}$, and resolution for wavelength $(3.5 \mathrm{~nm})$. Samples are coated with gold. A scanning electron microscope (SEM) is used to examine the surface morphology of conventionally and UV/ozone treated polyester and nylon fabrics.

2.3.2. Mechanical Testing. The tensile strength and percentage elongation at break of untreated and treated samples for different periods were carried out according to the Standard Method (ASTM 2000) using a Shimadzu Universal Tester of (C.R.T)-type S-500 Japan.

2.3.3. Fourier Transform Infrared Spectroscopy with Attenuation Total Reflection (ATR-FTIR). ATR-FTIR spectra of the above mentioned samples were recorded by means of Nicolet 380 Spectrometer using a zinc selenide crystal, in the wavelength range $650-4000 \mathrm{~cm}^{-1}$. To ensure reproducible contact between the crystal face and the fabric, a pressure of about $18 \mathrm{Kpa}$ is applied to the crystal holder. The ATR-FTIR absorbance frequencies for the treated samples are recorded with an average of 128 scans using a resolution of $4 \mathrm{~cm}^{-1}$. 


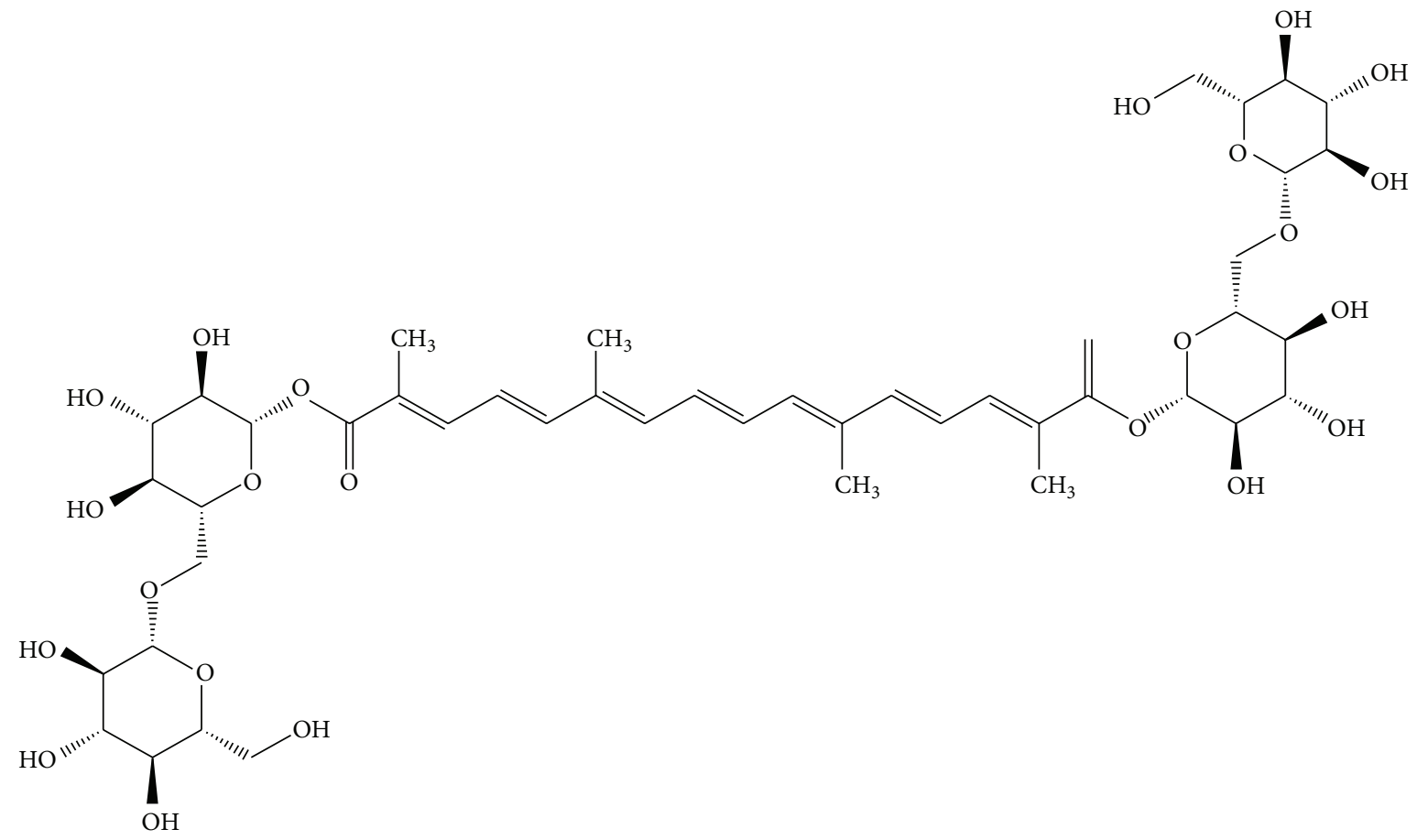

FIgURE 2: Chemical structures of saffron.

2.3.4. Colour Strength $(K / s)$ and Colour Parameters Determination. These measurements were carried out using Colour Eye 3100 Spectrophotometer SDL, England. The colour strength $(K / s)$ values of the different examined samples were determined from the reflection spectra values at the proper wavelength according to Kubelka Munk equation (AATCC, 1991) as follows:

$$
\frac{K}{s}=\frac{(1-R)^{2}}{2 R},
$$

where " $R$ " is the decimal fraction of the reflectance of dyed fabric.

These $(K / s)$ values represent the dyeability of the different treated and untreated samples.

\subsubsection{Assessment of Color Fastness}

(1) Fastness to Washing. The different (treated and untreated with UV/Ozone) dyed samples were stitched between two pieces of undyed cotton fabric (all fabric pieces had the same diameter) and then washed at $50^{\circ} \mathrm{C}$ for $30 \mathrm{~min}$. The staining of the undyed adjacent fabric was assessed according to the following grey scale: 1 , poor; 2 , fair; 3 , moderate; 4 , good; 5 , excellent (ISO 105-C01:1998).

(2) Fastness to Light. The different (treated and untreated with $\mathrm{UV} / \mathrm{O}_{3}$ ) dyed samples are exposed to artificial daylight for 100 hours using Tera Light Fastness Tester [9] at temperature $25 \pm 2^{\circ} \mathrm{C}$ and relative humidity $65+5 \%$ alongside with a Standard Grey Scale. The light fastness values are assessed visually according to the Standard Method (ISO 105:1997).

\section{Results and Discussion}

3.1. SEM Analysis. The SEM images of the polyester and nylon fabrics in Figures 3 and 4 show that the untreated fabric has fairly smooth surface, and the existence of few small particles on the surface of the fibers are probably due to the insufficient removal of the chemicals during the washing stage. However, the surface morphology of the treated fabrics has been changed dramatically and there are different features on the surface of the fibers, such as grooves and voids and nanoscale surface roughness [13]. This modification may be owed to the etching of the fiber surface happening after the bombardment of the surface of the fibers with ions and free radicals. This surface roughening effect leads to either a light trapping phenomenon due to destructive interference or increase in the dyeing rate of the fiber, which is a consequence of increasing the surface area of the fiber. Both of these effects may be the reason for the increase in the $K / s$ of the fabrics after the treatment. UV/Ozone irradiation long period may also cause degree of oxidation with significant depth.

3.2. The Effect of the $U V / O_{3}$ Treatment on the Mechanical Testing of the Synthetic Fabrics. The changes in the mechanical properties (tensile strength and percentage elongation at break) of blank unexposed polyester and nylon fabrics and those exposed to $\mathrm{UV} / \mathrm{O}_{3}$ treatments are evaluated and the obtained results are represented in Table 1 . These results showed that both the tensile strength and percentage elongation decreased. The changes in the mechanical properties of the examined fabric during exposure reflect not only the changes in the chemical structure of its polymer system but its supper molecular organization, that is, its morphology. Thus, 


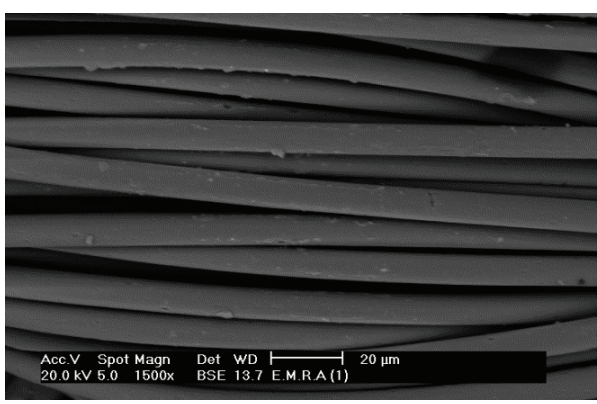

(a)

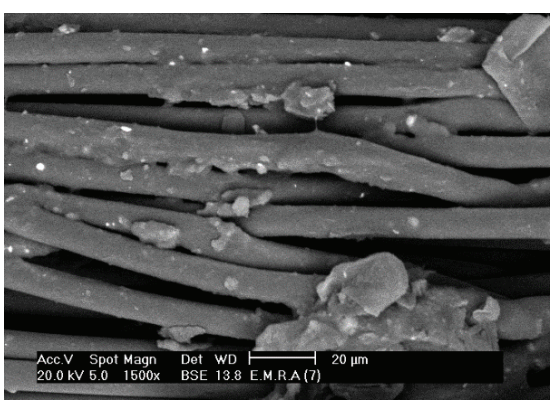

(b)

Figure 3: The SEM image of the polyester fabrics, (a) untreated sample, (b) treated sample, $\times 1500$.

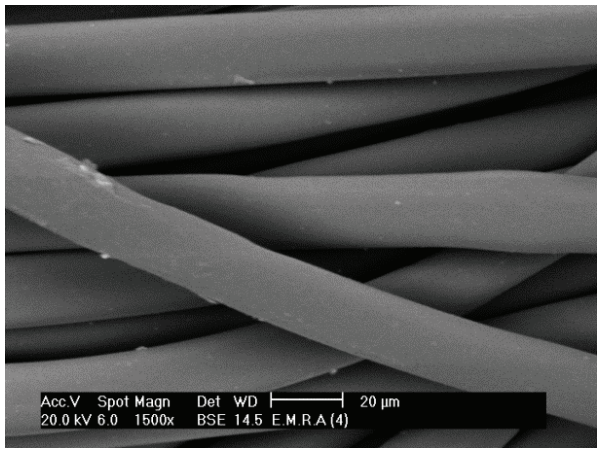

(a)

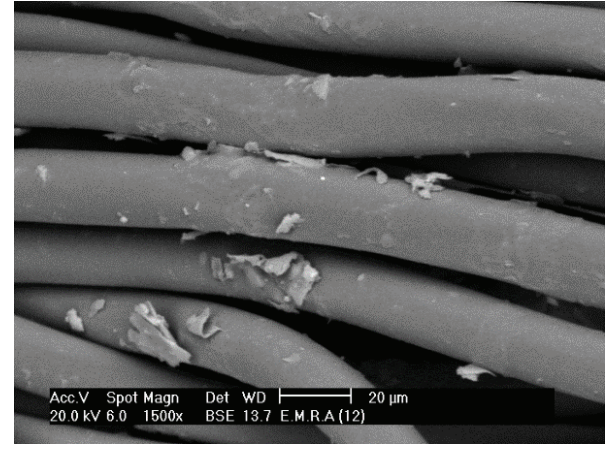

(b)

Figure 4: The SEM image of the nylon fabrics, (a) untreated sample, (b) treated sample, $\times 1500$.

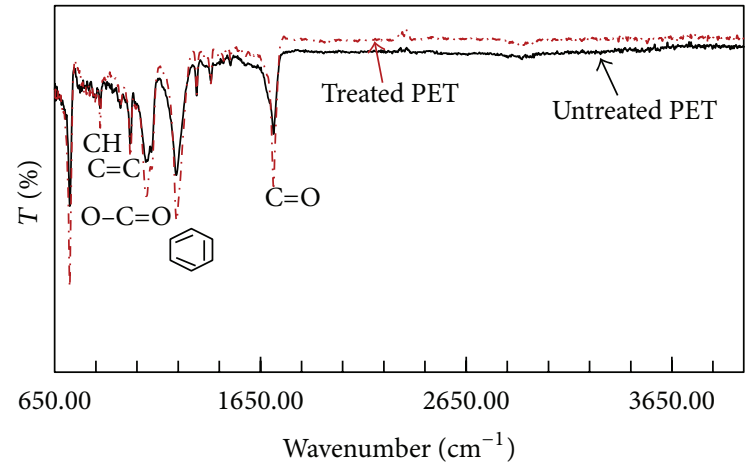

FIgURE 5: ATR-FTIR spectra of untreated and treated PET fabric.

these results assumed that the examined polyester and nylon samples had lost part of its strength by UV/Ozone treatment especially for the nylon fibers which may be due to the fact that such treatment had caused a removal of the surface layer of the synthetic fabrics. Due to the irradiation to UV/Ozone a degree of oxidation of the bulk polymer may also occur.

3.3. The Effect of UV/Ozone Treatment on the Fourier Transform Infrared Spectroscopy with Attenuation Total Reflection (ATR-FTIR) of Synthetic Fabrics. The ATR-FTIR spectroscopic technique was employed to study the effect of $\mathrm{UV} /$ Ozone treatment on the \% reflection values as a function

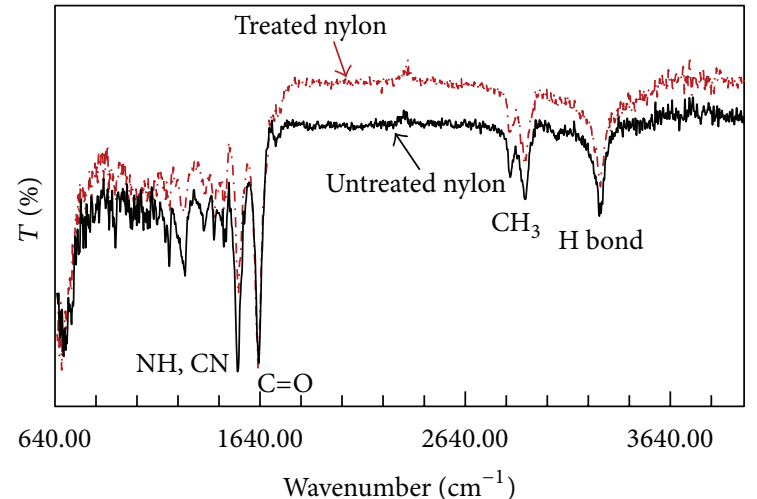

FIgURE 6: ATR-FTIR spectra of untreated and treated nylon fabric.

of the wave number in the range from 4000 to $500 \mathrm{~cm}^{-1}$ of the major function time. Figures 5 and 6 show the spectra of untreated and UV/Ozone treated polyester and nylon fabrics. Figure 5 shows IR spectra of the polyester fabric. The waves were assigned as follows: $1717 \mathrm{~cm}^{-1}(\mathrm{C}=\mathrm{O})$, $1407 \mathrm{~cm}^{-1}$ (aromatic ring), $1339 \mathrm{~cm}^{-1}$ and $1014 \mathrm{~cm}^{-1}$ (carboxylic ester or anhydride), $1092 \mathrm{~cm}^{-1}$ and $1014 \mathrm{~cm}^{-1}(\mathrm{O}=\mathrm{C}-$ O-C or secondary alcohol), $971 \mathrm{~cm}^{-1}(\mathrm{C}=\mathrm{C}), 872 \mathrm{~cm}^{-1}$ (five substituted $\mathrm{H}$ in benzene), $847 \mathrm{~cm}^{-1}$ (two neighboring $\mathrm{H}$ in benzene), and $724 \mathrm{~cm}^{-1}$ (heterocyclic aromatic ring). The 
TABLE 1: The changes in the mechanical properties of the tested fabrics with UV/Ozone irradiation.

\begin{tabular}{lcccc}
\hline Fabric & Polyester & & \multicolumn{2}{c}{ Nylon } \\
& Tensile (Kg.f) & Elongation (\%) & Tensile (Kg.f) & Elongation (\%) \\
\hline Untreated & 425.5 & 18.30 & 678.0 & 22.80 \\
Treated & 382.8 & 12.40 & 240.3 & 12.40 \\
\hline
\end{tabular}

TABLE 2: Effect of exposure time on washing fastness of polyester dyed samples.

\begin{tabular}{|c|c|c|c|c|}
\hline \multirow{2}{*}{ Exposure time (min) } & \multicolumn{2}{|c|}{ Curcumin dye } & \multicolumn{2}{|c|}{ Saffron dye } \\
\hline & Staining & Alteration & Staining & Alteration \\
\hline 0 (untreated) & 5 & $2 / 3$ & 5 & 4 \\
\hline 5 & $4 / 5$ & $2 / 3$ & 5 & 4 \\
\hline 20 & $4 / 5$ & 3 & 5 & $4 / 5$ \\
\hline 50 & $4 / 5$ & 3 & 5 & $4 / 5$ \\
\hline 110 & $4 / 5$ & 3 & 5 & $4 / 5$ \\
\hline 120 & $4 / 5$ & 3 & 5 & $4 / 5$ \\
\hline
\end{tabular}

main structure of the polyester sample had ester, alcohol, anhydride, aromatic ring, and heterocyclic aromatic rings. Alcohol was able to react with anhydride and produce ester groups. That was the reason there was still alcohol and anhydride as residual reactants left in the polyester. The carboxyl, ester, anhydride, and alcohol groups showed the polyester fabric was not pure PET. The peak at $1407 \mathrm{~cm}^{-1}$ corresponded to the aromatic ring which was a stable group. It was the characteristic absorption peak of PET. The peaks at 1717 and $1092 \mathrm{~cm}^{-1}$ were assigned to the ester group which preferred to break under certain conditions. From Figure 5 the increment of the intensity of the most characteristic groups due to oxidation effect caused by photochemical interactions and polymer degradation [14-19] is clear.

Figure 6 showed that the characteristic bands of the nylon fibers were observed at $3300 \mathrm{~cm}^{-1}$ with an overtone at $3080 \mathrm{~cm}^{-1}$ due to the stretching of hydrogen bonded to the $\mathrm{N}-\mathrm{H}$ and the $\mathrm{N}-\mathrm{H}$ bending. The $\mathrm{CH}_{2}$ symmetric and asymmetric stretching were found at 2930 and $2854 \mathrm{~cm}^{-1}$, associated at $720 \mathrm{~cm}^{-1}$ with the vibration of 4 or more $-\mathrm{CH}_{2}$ groups in the polymer chain. The band at $1634 \mathrm{~cm}^{-1}$ is associated with the $\mathrm{C}=\mathrm{O}$ stretching and the $1535 \mathrm{~cm}^{-1}$ band is due to a combination of the bending $\mathrm{N}-\mathrm{H}$ band and the stretching of the $\mathrm{C}-\mathrm{N}$ [20-25]. It is clear that the intensity of $\mathrm{C}=\mathrm{O}$ and $\mathrm{CO}$ increased due to the UV/Ozone irradiation while the other characteristic groups were slightly degreased.

\subsection{The Effect of Different UV/Ozone Treatment Times on the} $\mathrm{K} / \mathrm{s}$ Values of the Dyed Synthetic Fabrics. Molecular oxygen was subjected to irradiation at $184.9 \mathrm{~nm}$ and $253.7 \mathrm{~nm}$ leading to absorption of hydrocarbons and the formation of ozone [26] and form active chemical sites. The products underwent UV/ozone excitation with atomic oxygen to form simpler, volatile molecules, which desorbed from the surfaces that has roughness at the nanoscales [13]. Therefore, when both wavelengths were present atomic oxygen was continuously generated and ozone was continually formed and then destroyed [26-29].

Figures 7 and 8 show the effect of different UV/Ozone treatment times on the $K / s$ values of the two examined synthetic fabrics (polyester and nylon) dyed with saffron and curcumin dyes. As is evident, increasing the UV/Ozone treatment time $(5,20,50,110$, and $120 \mathrm{~min})$ brings about a noticeable increase in the $K / s$ value; this probably due to the diffusion of larger amount of dye into fabrics under study.

Increasing $\mathrm{K} / \mathrm{s}$ of the UV/ozone treated fabrics than untreated fabrics may be attributed to the fact that interaction of UV in presence of oxygen on the polymeric materials (polyester and nylon fabrics) produces many free radicals ( $\mathrm{P}^{\bullet}$, $\mathrm{POO}^{\circ}, \mathrm{HOO}^{\circ}, \mathrm{H}^{\bullet}, \mathrm{HO}^{\circ}$ ) as explained in Figure 9. Increase of $\mathrm{K} / \mathrm{s}$ values can be also be attributed to the affinity increase of dye molecules with the new functional groups generated during the treatment $(\mathrm{C}-\mathrm{O}, \mathrm{C}=\mathrm{O}, \mathrm{COOH})$ but not in a radical state. These free radicals are responsible for making active sites for the attachment of treatment solutions (saffron or curcumin dye molecules) to the polyester and nylon fabrics.

\subsection{The Effect of the $U V / O_{3}$ Treatment on the Fastness Proper- ties of the Synthetic Fabrics}

3.5.1. Washing Fastness. The colour fastness to washing of the different examined dyed samples was determined according to standard methods (AATCC, 61-1975, 8-1977).

The results of washing fastness for all of the examined samples are summarized in Tables 2 and 3. These data showed that there was a slight effect of $\mathrm{UV} / \mathrm{O}_{3}$ treatment in improving washing fastness. Washing fastness assessment of obtained colors on polyester and nylon fibers have shown good levels.

3.5.2. Light Fastness. The light fastness results are good and acceptable showing little fading of light shades in both the treated and untreated dyed nylon and polyester fabrics. The 
TABLE 3: Effect of exposure time on washing fastness of nylon dyed samples.

\begin{tabular}{|c|c|c|c|c|}
\hline \multirow{2}{*}{ Exposure time (min) } & \multicolumn{2}{|c|}{ Curcumin dye } & \multicolumn{2}{|c|}{ Saffron dye } \\
\hline & Staining & Alteration & Staining & Alteration \\
\hline 0 (untreated) & 3 & 4 & 5 & 4 \\
\hline 5 & 3 & 4 & 5 & 4 \\
\hline 20 & $3 / 4$ & $4 / 5$ & 5 & $4 / 5$ \\
\hline 50 & $3 / 4$ & $4 / 5$ & 5 & $4 / 5$ \\
\hline 110 & $3 / 4$ & $4 / 5$ & 5 & $4 / 5$ \\
\hline 120 & $3 / 4$ & $4 / 5$ & 5 & $4 / 5$ \\
\hline
\end{tabular}

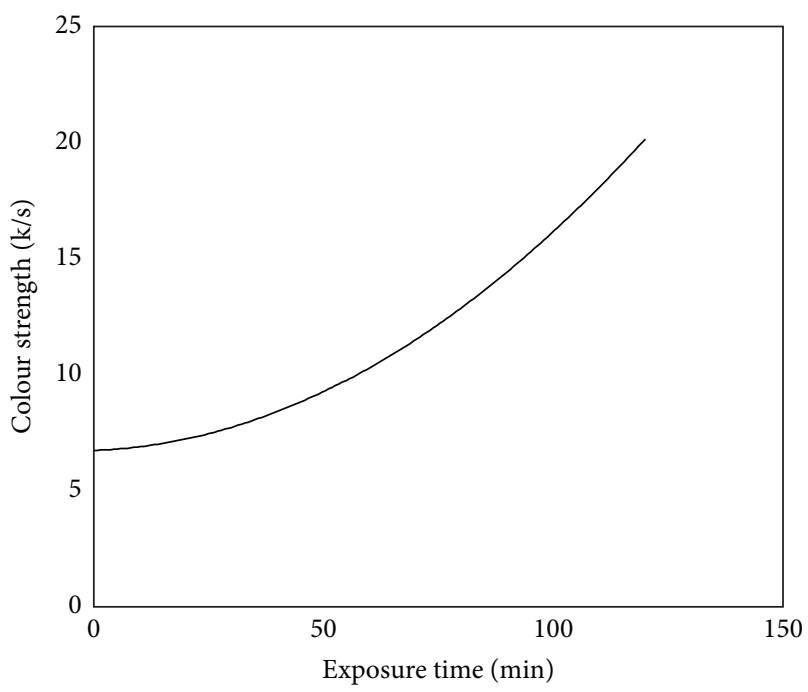

(a)

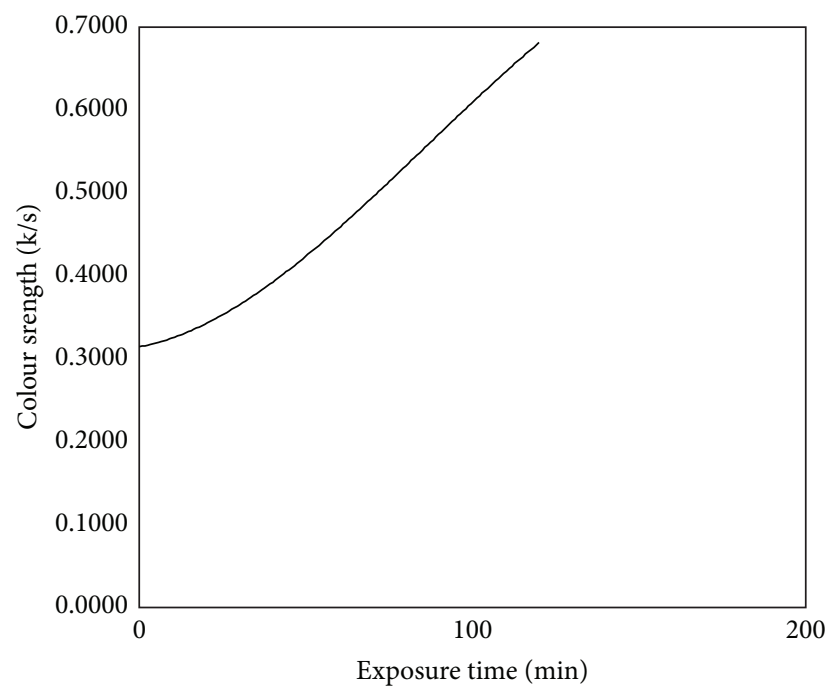

(b)

Figure 7: The $K / s$ values of polyester fabrics, (a) curcumin dye, (b) saffron dye.

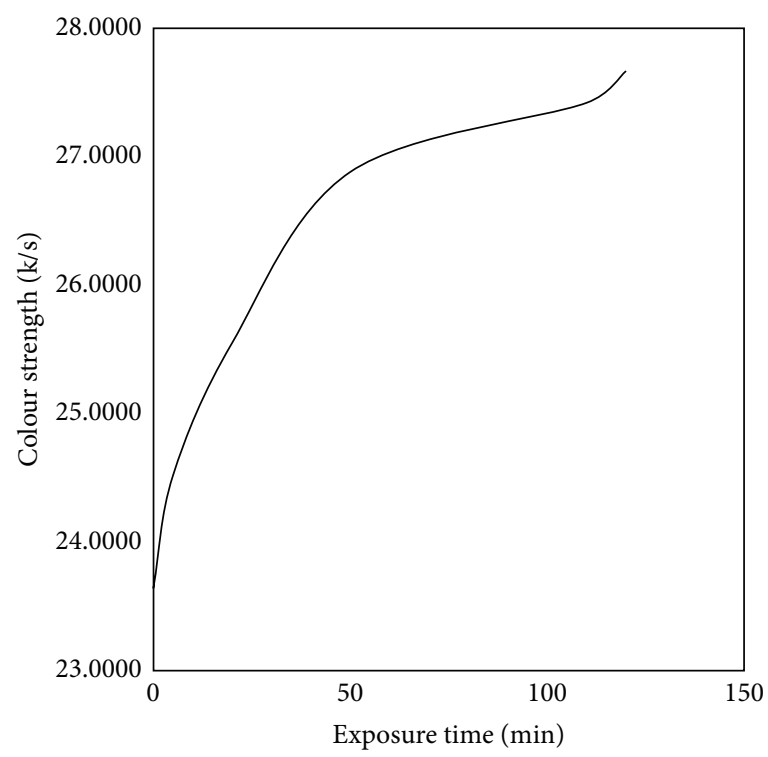

(a)

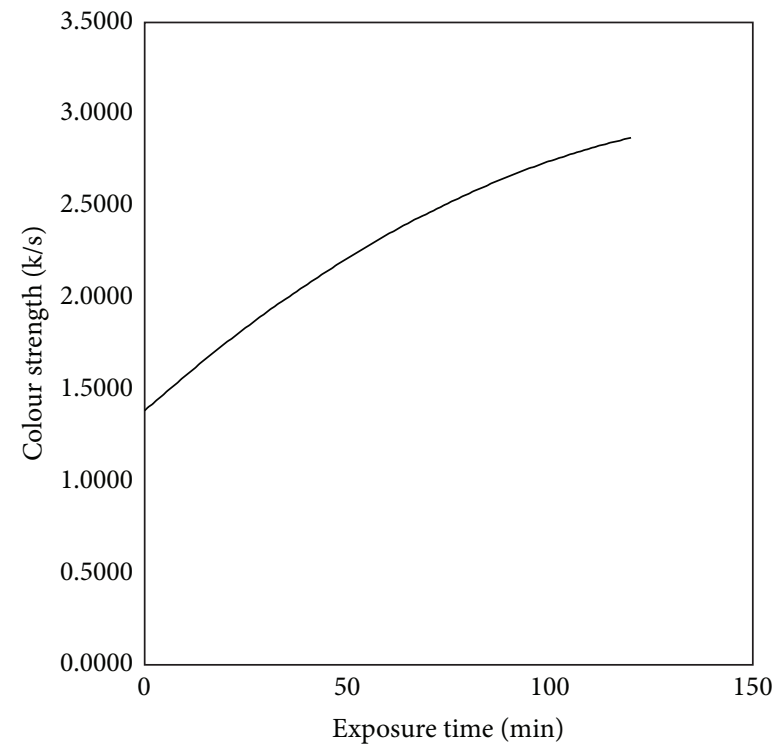

(b)

Figure 8: The $K / s$ values of nylon fabrics, (a) curcumin dye, (b) saffron dye. 


$$
\begin{aligned}
& \mathrm{PH} \stackrel{h \nu / \mathrm{O}_{2}}{\longrightarrow} \mathrm{P}^{\bullet}+\mathrm{H}^{\bullet} \\
& \mathrm{P}^{\bullet}+\mathrm{O}_{2} \longrightarrow \mathrm{POO}^{\bullet}
\end{aligned}
$$

Hydrogen abstraction $\mathrm{POO}^{\bullet}+\mathrm{PH}^{\bullet} \longrightarrow \mathrm{POOH}+\mathrm{P}^{\bullet}$

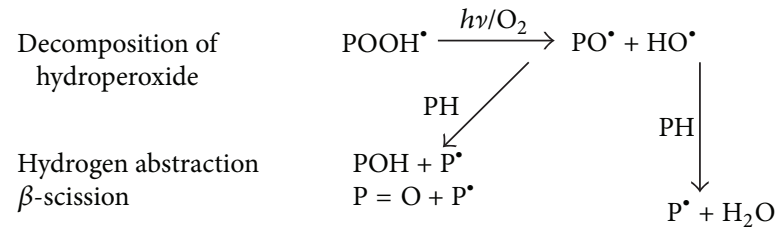

FIGURE 9: Effect of $\mathrm{UV} / \mathrm{O}_{3}$ radiation on polymeric materials.

TABLE 4: Effect of exposure time on light fastness of polyester dyed samples.

\begin{tabular}{lcc}
\hline Exposure time $(\mathrm{min})$ & Curcumin dye & Saffron dye \\
\hline 0 (untreated) & 2 & 2 \\
5 & $2 / 3$ & $2 / 3$ \\
20 & $2 / 3$ & $2 / 3$ \\
50 & 3 & $2 / 3$ \\
110 & 3 & 3 \\
120 & 3 & 3 \\
\hline
\end{tabular}

TABLE 5: Effect of exposure time on light fastness of nylon dyed samples.

\begin{tabular}{lcc}
\hline Exposure time $(\mathrm{min})$ & Curcumin dye & Saffron dye \\
\hline 0 (untreated) & 2 & 2 \\
5 & $2 / 3$ & 2 \\
20 & $2 / 3$ & $2 / 3$ \\
50 & 3 & $2 / 3$ \\
110 & 3 & 3 \\
120 & 3 & 3 \\
\hline
\end{tabular}

results of light fastness for all of the examined samples are summarized in Tables 4 and 5.

\section{Conclusion}

This work can conclude that treating nylon and polyester under study by UV/Ozone for different time ranged from 0 to $120 \mathrm{~min}$ increased the dyeability of both fabrics with curcumin and saffron natural dyes. Dyeability of both fabrics was measured according to colour strength $(K / s)$ and fastness to washing and light fastness. Treatment with UV/ozone showed marked change of the surface chemical structure as shown by ATR-ATR-FTIR measurements in addition to the surface morphology as shown by SEM images.

\section{Conflict of Interests}

The authors declare that there is no conflict of interests regarding the publication of this paper.

\section{Acknowledgments}

The authors thank Faculty of Applied Arts, Damietta University, and National Institute for Standards, Ministry of Scientific Research, for offering the facilities to conduct most of the experimental part of this study.

\section{References}

[1] M. P. Gashti, J. Willoughby, and P. Agrawal, "Surface and bulk modification of synthetic textiles to improve dyeability," in Textile Dyeing, P. J. Hauser, Ed., chapter 13, InTech, Rijeka, Croatia, 2011.

[2] C. Silva and A. Cavaco-Paulo, "Biotransformations in synthetic fibres," Biocatalysis and Biotransformation, vol. 26, no. 5, pp. 350-356, 2008.

[3] T. A. Elmaaty, K. Elnagar, S. Hassan, and H. Gamal, "Antibacterial activity and dyeing characteristics of some azo-pyazole disperse dyes using eco-friendly ultrasound energy for PET fabric," International Journal of Scientific \& Engineering Research, vol. 5, no. 5, pp. 1156-1161, 2014.

[4] K. J. Lee, C. Kim, K. Ho, and K. Constant, "Improved surface wettability of polyurethane films by ultraviolet ozone treatment," Journal of Applied Polymer Science, vol. 118, no. 5, pp. 3024-3303, 2010.

[5] N. A. Elzaher and M. N. Micheal, "Time optimization of ultraviolet-ozone pretreatment for improving wool fabrics properties," Journal of Applied Polymer Science, vol. 85, no. 7, pp. 1469-1476, 2002.

[6] A. K. Samanta and A. Konar, "Dyeing of textiles with natural dyes," in Natural Dyes, E. P. A. Kumbasar, Ed., chapter 3, p. 132, InTech, Rijeka, Croatia, 2011.

[7] F. A. Nagia and R. S. EL-Mohamedy, "Dyeing of wool with natural anthraquinone dyes from Fusarium oxysporum," Dyes and Pigments, vol. 75, no. 3, pp. 550-555, 2007.

[8] S. F. Ibrahim, K. El-Nagar, and F. M. Tera, "Improving wool printability at reduced energy using UV/ozone treatment," Research Journal of Textile and Apparel. In press.

[9] K. Elnagar, S. M. Reda, H. E. Ahmed, and S. Kamal, "Studying irradiation homogeneity in light aging for historical textile conservation," Fibers and Polymers, vol. 14, no. 9, pp. 1581-1585, 2013.

[10] S. Urbeen, S. Ali, T. Hussain, and R. Nawaz, "Dyeing properties of natural dyes extracted from turmeric and their comparison with reactive dyeing," Research Journal of Textile and Apparel, vol. 12, no. 4, 2008.

[11] K. Sachan and V. P. Kapoor, "Optimization of extraction and dyeing conditions for traditional turmeric dye," Indian Journal of traditional Knowledge, vol. 6, no. 2, pp. 270-278, 2007.

[12] A. S. Raja, P. K. Pareek, D. B. Shakyawar, S. A. Wani, F. A. Nehvi, and A. H. Sofi, "Extraction of natural dye from Saffron flower waste and its application on pashmina fabric, Pelagia Research Library," Advances in Applied Science Research, vol. 3, no. 1, pp. 156-161, 2012.

[13] J. Jang and Y. Jeong, "Nano roughening of PET and PTT fabrics via continuous $\mathrm{UV} / \mathrm{O}_{3}$ irradiation," Dyes and Pigments, vol. 69, no. 3, pp. 137-143, 2006.

[14] X. Song, H. Liu, L. Cheng, and Y. Qu, "Surface modification of coconut-based activated carbon by liquid-phase oxidation and its effects on lead ion adsorption," Desalination, vol. 255, no. 1-3, pp. 78-83, 2010. 
[15] D. L. Pavia, G. M. Lampman, and G. S. Kriz, Introduction to Spectroscopy, Thomson Business Information India Pvt., Bangalore, India, 3rd edition, 2006.

[16] V. Bajpai, A. Dey, S. Ghosh, S. Bajpai, and M. K. Jha, "Quantification of bacterial adherence on different textile fabrics," International Biodeterioration and Biodegradation, vol. 65, no. 8, pp. 1169-1174, 2011.

[17] L. Li, M. Frey, and K. J. Browning, "Biodegradability study on cotton and polyester fabrics," Journal of Engineered Fibers and Fabrics, vol. 5, no. 4, pp. 42-53, 2010.

[18] Y. Zhang, Y. Su, J. Peng et al., "Composite nanofiltration membranes prepared by interfacial polymerization with natural material tannic acid and trimesoyl chloride," Journal of Membrane Science, vol. 429, pp. 235-242, 2013.

[19] M. Minhalma and M. N. de Pinho, "Tannic-membrane interactions on ultrafiltration of cork processing wastewaters," Separation and Purification Technology, vol. 22-23, pp. 479-488, 2001.

[20] Z. Wu, C. Zhou, R. Qi, and H. Zhang, "Synthesis and characterization of nylon 1012/clay nanocomposite," Journal of Applied Polymer Science, vol. 83, no. 11, pp. 2403-2410, 2002.

[21] S. G. Gholap, D. A. Musale, S. S. Kulkarni, S. K. Karode, and U. K. Kharul, "Protein and buffer transport through anionically grafted nylon membranes," Journal of Membrane Science, vol. 183, no. 1, pp. 89-99, 2001.

[22] E. M. Enlow, J. L. Kennedy, A. A. Nieuwland, J. E. Hendrix, and S. L. Morgan, "Discrimination of nylon polymers using attenuated total reflection mid-infrared spectra and multivariate statistical techniques," Applied Spectroscopy, vol. 59, no. 8, pp. 986-992, 2005.

[23] R. Iwamoto and H. Murase, "Infrared spectroscopic study of the interactions of nylon-6 with water," Journal of Polymer Science. Part B: Polymer Physics, vol. 41, no. 14, pp. 1722-1729, 2003.

[24] B. Stuart, Infrared Spectroscopy: Fundamentals and Applications, John Wiley \& Sons, 2004.

[25] A. A. Younis, M. A. Nour, and K. El-Nagar, "Studying the effect of phosphorylated sol-gel on polyester fabric as flame-retardant coating," Applied Chemistry-Elixir International Journal, vol. 70, pp. 24230-24235, 2014.

[26] M. N. Michael and N. A. El-Zaher, "Invistigation into the effect of UV/ozone treatment on dyeing properties of natural fabrics," Egyptian Journal of Chemistry, vol. 47, no. 1, pp. 93-100, 2004.

[27] F. Fattahi, H. Izadan, and A. Khoddami, "Investigation into the effect of UV/Ozone irradiation on dyeing behaviour of poly(lactic acid) and poly(ethylene terephthalate) substrates," Progress in Color, Colorants and Coatings, vol. 5, pp. 15-22, 2012.

[28] S. F. Ibrahim, Investigation into the effect of UV/ozone treatments on physical properties and dyeing kinetics of some polymeric fabrics [Ph.D. thesis], Faculty of Science, Cairo University, Cairo, Egypt, 2003.

[29] E. M. Osman, M. N. Michael, and H. Gohar, "the effect of both UV/Ozone and chitosan on natural fabrics," International Journal of Chemistry, vol. 2, no. 2, pp. 28-39, 2010. 

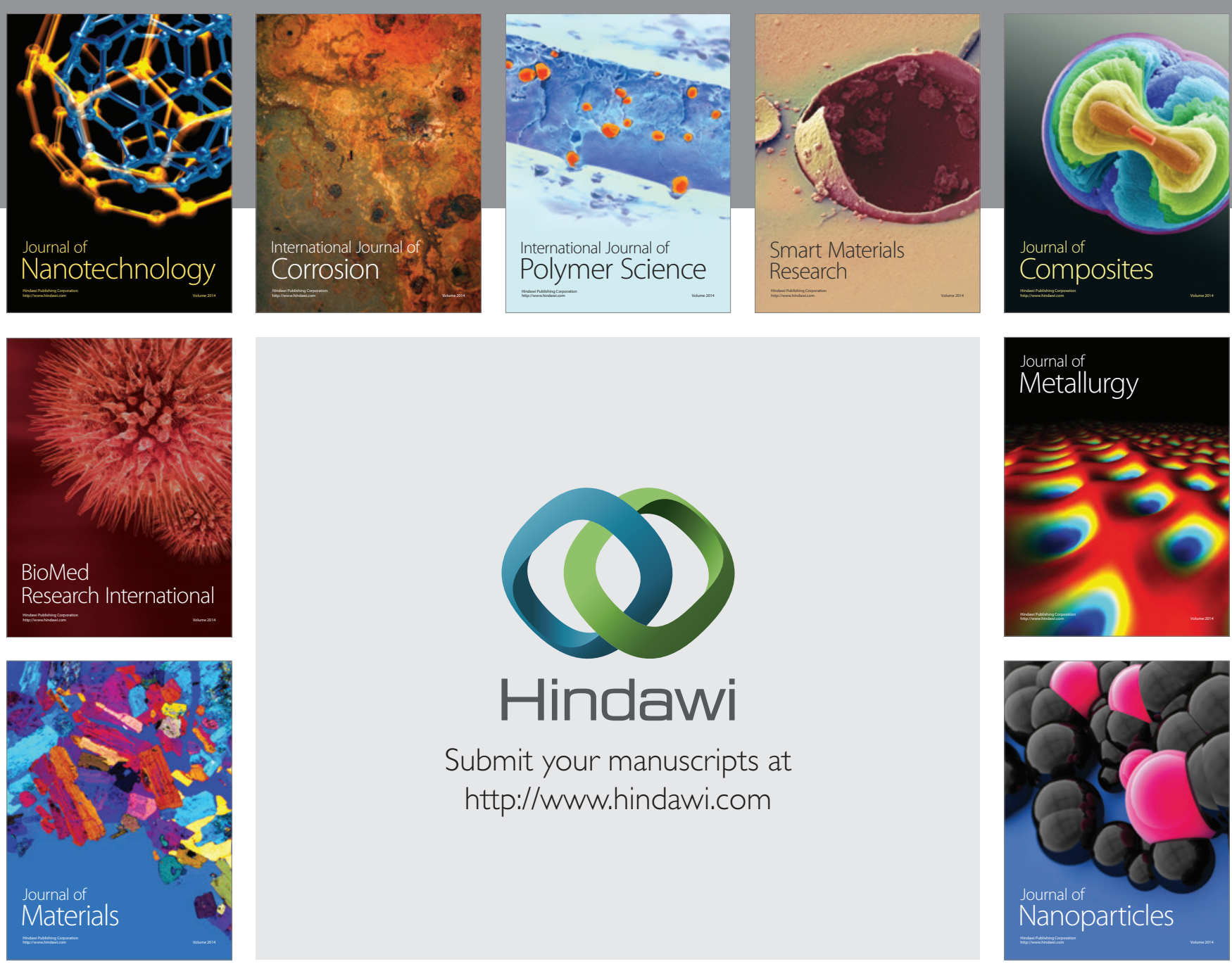

Submit your manuscripts at http://www.hindawi.com
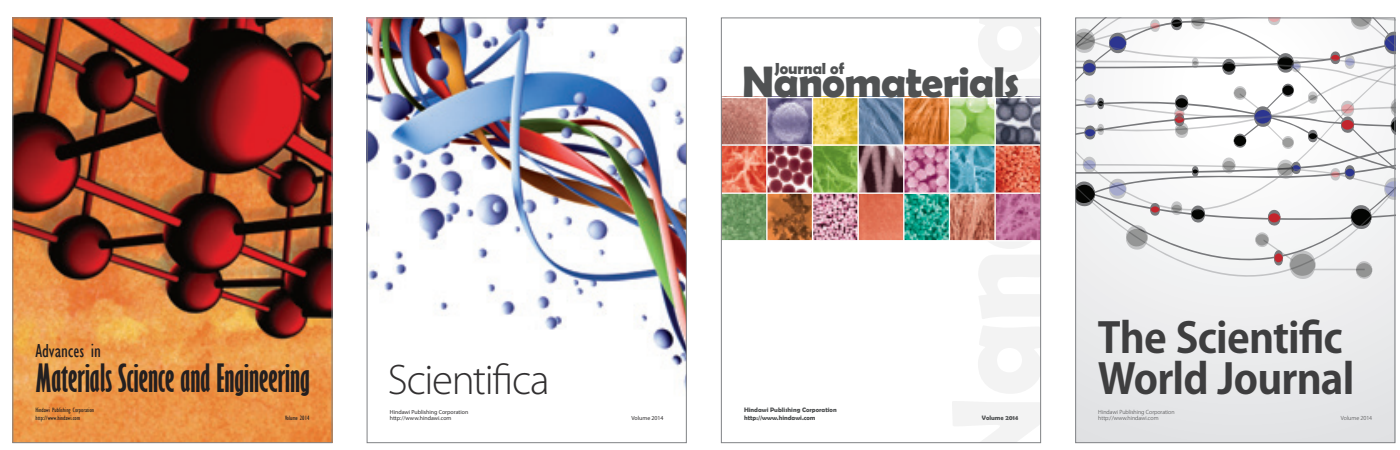

\section{The Scientific World Journal}
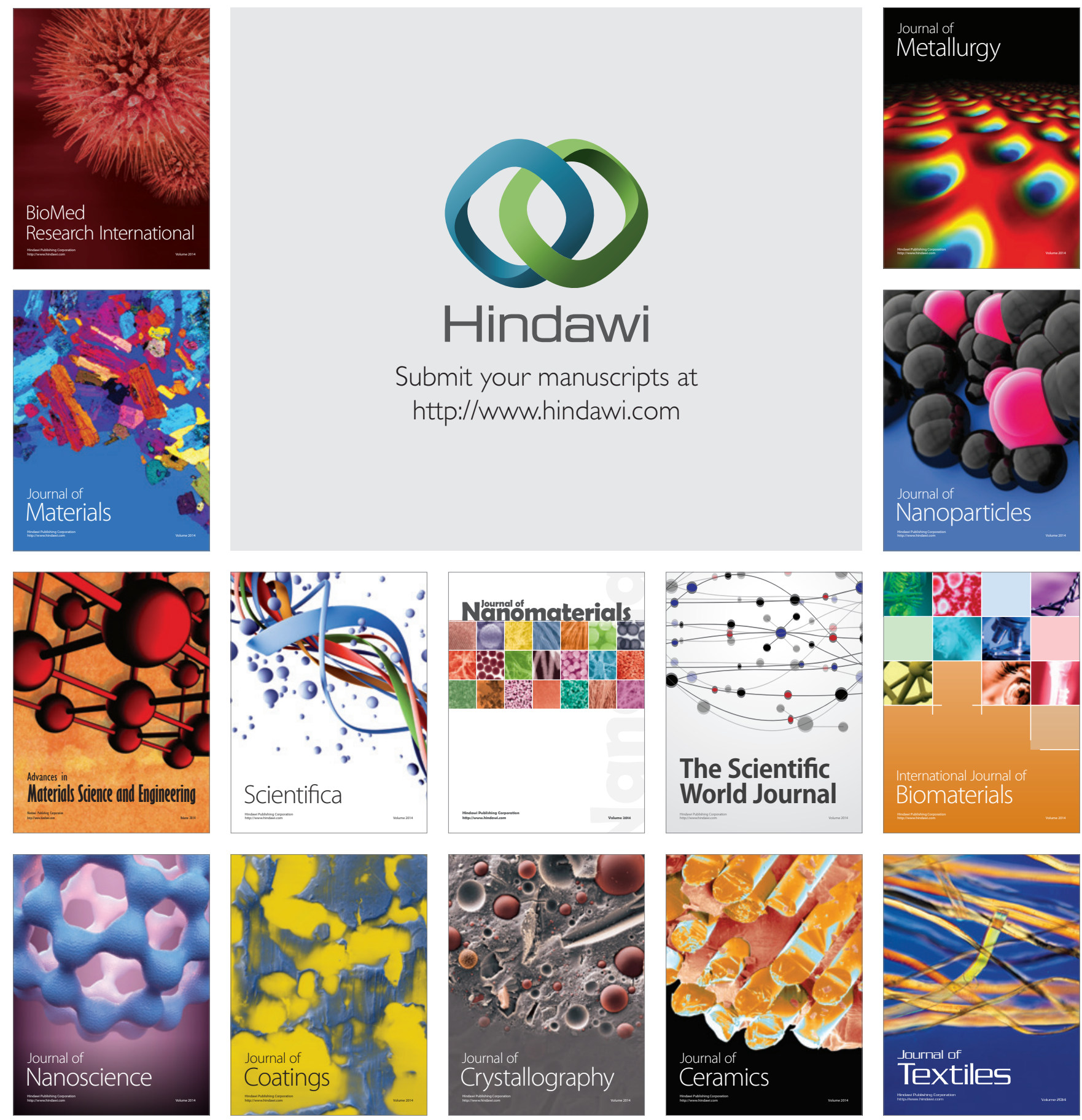